\title{
A Comparison Of The Elements Of Motivation In The Hospital Industry Versus The Retail And Manufacturing Sectors
}

Rickey Casey, D.B.A., University of the Ozarks, USA Jay Robbins, D.B.A. Ouachita University, USA

\begin{abstract}
This study compared the results from a survey of 200 employees from a manufacturing plant, 330 from a major retailer, and 89 employees from a hospital. The Hackman and Oldham Model have been tested in several industries, and have developed averages for the manufacturing and sales industries. This study takes the Skills Application 4.2 Job Diagnostic survey and evaluated the service industry. The article compared the results of all three surveys and developed a Motivating Potential Score. The study made some very interesting observations about the manufacturing, retail and service industry.
\end{abstract}

Keywords: Motivation, Hackman \& Oldham, Job Characteristics Model

\section{INTRODUCTION}

\begin{abstract}
n order to survive in today's global economy; many U.S. companies are downsizing or reorganizing. c Unfortunately, this strategy does not consider the effects of this decision on the motivation of the individual.

This strategy has proven to be flawed. When a workforce has been downsized or reorganized, the result is employees could be assigned to new positions that they perceive as not challenging. Performance could then decline, and have a significant negative influence on productivity.
\end{abstract}

The Hackman \& Oldham Model was developed to specify how job characteristics and individual differences interact to affect the satisfaction, motivation and productivity of individuals at work. The model is helpful in planning and carrying out changes in the design of jobs.

In developing their model, Hackman \& Oldham (1976) built upon the foundation of Herzberg's two-factor theory (Herzberg, Mausner \& Synderman, 1959) with some theoretical underpinnings directly from the expectancy theory (Evans, Kiggundu \& House, 1979).

A study by Oldham (1976) examined: (a) the relationship between the internal work motivation of employees and their job performance and (b) the moderating effect of individual growth need strength, co-worker satisfaction, and supervisory satisfaction on the relationships between several job characteristics and internal motivation. This study relied upon work by Hackman \& Lawler (1971) and Hackman \& Oldham (1976). The results also supported studies by Alderfer (1967); Lawler, Hackman, \& Kaufman (1973); and Herzberg's (1966) two-factor theory. Herzberg suggested further research should be done to examine how the work environment moderates or affects the job characteristicsinternal motivation relationship (Oldham, 1976).

A review of the literature suggests that empirical investigations of the Job Characteristics Model did not systematically explore the moderating effects of growth need strength (GNS) and context satisfaction (pay, job security, co-worker, and supervision) on the relations among core job characteristics, critical psychological states, and worker outcomes. One study attempted to assess the extent to which Job Diagnostic Survey and each of the four context satisfactions moderate the relations between each job characteristic, and its associated psychological state, and the 
relations between each psychological state and three work outcomes: overall (general) job satisfaction, growth satisfaction, and internal motivation. The study also sought to extend the work of Hackman \& Oldham. But the data of this study generally did not support either the joint moderating effect of GNS or the context satisfaction on the relations among job characteristics, psychological states, and motivational and affective results. Future research should include other relevant work outcomes, in particular, indices of performance (Tiegs, Terick \& Fried, 1992).

When firms are considering downsizing or restructuring, they could use the Hackman \& Oldham model to redesign jobs, maximize motivation, and improve their overall ability to compete in the global marketplace.

\section{STATEMENT OF THE PROBLEM}

The Hackman \& Oldham Theory has been tested in several areas but needs additional testing and verification in the service area. Existing research has yielded inconsistent results and has made it difficult to extrapolate results of the studies. This paper consists of a survey of a major retail company, a electric motor manufacturer and a hospital. This allowed the researchers to compare the model in the retail, manufacturing and service industry.

\section{PURPOSE}

The purpose of this study is to generate information and add to the body of knowledge concerning Hackman \& Oldham's Theory as it relates to the motivation of the workforce in the manufacturing arena.

This study will use the Hackman \& Oldham's Job Characteristics Theory as the underlying theory. Several studies have supported the theory, and some did not support their findings. This study will examine the effects of job design on the behavior of human performers. The study will use Hackman \& Oldham's Theory, with emphasis in how the theory can be most useful in carrying out redesign activities and observing both management and employees to determine the validity of the theory in a Hospital and relate the results to the retail and service industries. .

\section{DEFINITIONS OF KEY TERMS}

The researcher will present definitions that will be very important in this research study. This will allow a common frame of reference. There are six areas that comprise the Job Characteristics Model (JCM) which is the focus of the study. Several key terms will be used in this research project.

The first major section of the JCM is the core job characteristics. The core job dimensions are made up of skill variety, task identity, task significance, autonomy and feedback (Hackman \& Oldham, 1975). Skill variety is the degree to which a job requires a variety of different activities that utilize the use of different skills and talents (Hackman \& Oldham, 1975).

Task identity is the degree to which the job requires completion of a whole and identifiable piece of work--that is doing a job from beginning to end with a visible outcome (Hackman \& Oldham, 1975). Task significance is the degree to which the job has a substantial impact on the lives or work of other people, whether in the immediate organization or in the external environment (Hackman \& Oldham, 1975). Autonomy is the degree to which the job provides substantial freedom, independence, and discretion to the individual in scheduling the work and in determining the procedures to be used in carrying it out (Hackman \& Oldham, 1975). Feedback from the job is the degree to which carrying out the work activities required by the job results in the individual's obtaining direct and clear information about the effectiveness of performance (Hackman \& Oldham, 1975).

The next major section of the JCM is the Critical Psychological States. The Critical Psychological States include experienced meaningfulness of the work, experienced responsibility for outcomes of the work, and knowledge of the actual results of the work activities (Hackman \& Oldham, 1975). Experienced meaningfulness of the work is how work can take on a personal meaning and how the work accomplishes something. The person must experience the work as generally important, valuable, and worthwhile. Three characteristics that affect this variable are skill variety, task identity and task significance (Hackman \& Oldham, 1975). 
Experienced responsibility for outcomes of the work is the variable that promotes a feeling of personal responsibility for the work outcomes. The individual must personally be responsible and accountable for the results of the work performed. The primary factor that impacts this variable is autonomy, which can increase or decrease this variable (Hackman \& Oldham, 1975).

Knowledge of the actual results of the actual work activities is the variable that deals with the results of one's work and the knowledge of the work. The individual must have an understanding, on a fairly regular basis, of how effectively he or she is performing the job. This variable is affected by the core job characteristic of feedback (Hackman \& Oldham, 1975).

The third major section of the JCM is the outcomes. The outcomes include high internal motivation, high growth satisfaction, high general job satisfaction and high work effectiveness (Hackman \& Oldham, 1975). High internal work motivation indicates the amount of motivation and satisfaction a worker will get from the job (Hackman \& Oldham, 1975). High growth satisfaction is gained from self-direction and from learning, and from personal accomplishment at work (Hackman \& Oldham, 1975). High general job satisfaction is the satisfaction or feeling of satisfaction with the overall job performance (Hackman \& Oldham, 1975). High work effectiveness can be defined as to be successful in the job a person is doing to feel the job has made a difference (Hackman \& Oldham, 1975).

The final section of the JCM is composed of the moderators. They are knowledge and skill, growth need strength, context satisfactions and relate to overall motivation (Hackman \& Oldham, 1975). Knowledge and skills deal with a worker having adequate knowledge and skill to perform a job adequately (Hackman \& Oldham, 1975). Growthneed strength is the need for considerable self-direction, learning, and personal accomplishment at work (Hackman \& Oldham, 1975). Context satisfaction is a variable that looks at how a person feels about their surroundings at work. This deals with such things as pay, job security, supervision, co-workers and other relationships at work (Hackman \& Oldham, 1975).

Motivating Potential Score (MPS) is the combination of the five dimensions above into a single index reflecting the overall potential of the job to prompt self-generated work motivation in job incumbents. MPS + (Skill Variety + Task Identity + Task Significance/3) X Autonomy X Job Feedback (Hackman \& Oldham, 1975).

Internal Motivation is also important in this model and represents the term used to describe the state of feeling good about oneself and what a person is producing as well as obtaining a sense of accomplishment. When one has high internal work motivation, feeling good about oneself is closely tied to how well he or she performs on the job (Hackman \& Oldham, 1975).

\section{RELIABILITY OF THE INSTRUMENTS}

The Job Diagnostic Survey is intended for use in (a) diagnostic activities to determine whether (and how) existing jobs can be improved to increase employee motivation, performance, and satisfaction; and (b) evaluation studies of the effects of work design.

Since the JDS was originally published (Hackman \& Oldham, 1974 \& 1975), the instrument has been used in many organizations and subjected to several empirical tests (Cathcart, Goddard, and Youngblood, 1978; Dunham, 1976; Dunham, Aldag \& Brief, 1977; Oldham, Hackman \& Stepina, 1979; Pierce \& Dunham, 1978; Stone, Ganster, Woodman \& Fuslier, in press; Stone \& Porter, 1977; Barr \& Aldag, 1978).

Experience with the JDS, and studies of its properties, have highlighted a number of limitations and suggest several cautions in using the JDS survey instrument. The Job Characteristics, as measured by the JDS, are not independent of one another. When a job is high on one characteristic (such as skill variety) it also tends to be high on one or more others (such as autonomy and/or feedback). The positive intercorrelations among the job characteristics may reflect problems in how they are measured in the JDS. Or, it may be that most "good" jobs really are good in many ways, and jobs that are poorly designed tend to be low on most or all of the job characteristics. The authors of the JDS are not sure if they have an instrument problem or an ecological phenomenon to overinterpret JDS scores for any single job characteristic considered

The authors of the 
instrument suggest it is just as good empirically-and usually-better to simply add up the scores of the five motivating job characteristics to get an overall estimate of formula for the motivating potential score (MPS) as it is to compute them individually. The advantage of the MPS score is that it derives directly from the motivational theory on which the JDS was based. The disadvantage is that computation of the score involves multiplying the job characteristics, which is generally a dubious proposition with measures that are less than perfectly reliable, and especially so when those measures tend to be intercorrelated.

Organization of the Study

This study will use the Job Diagnostic Survey and the Job Rating Form to survey approximately 500 workers and management of a large retail company. The survey will be given to workers and management from two subsidiaries of the retail company. The survey instrument will be scored and the results will be related to the Hackman and Oldham model of job characteristics model of work redesign and motivation.

The researcher has obtained the permission of the company to do the survey and the author of the survey instrument. The instrument is not under a copyright and may be copied and utilized. Appropriate statistical techniques will be used to evaluate the model and evaluate the hypotheses as outlined above.

Validity of the Instruments

The validity of some JDS scales remains unestablished, however, the JDS in general has been found to have satisfactory psychometric characteristics, and summary scores derived from the instrument have been shown to have substantive validity. Internal consistency reliabilities range from a high of .88 (growth need strength, in the "would like, format) to a low of .56 (Social satisfaction) to .28 (growth satisfaction). In general, the results suggest that both the validity of the items are satisfactory. While it is to the credit of the instrument that it discriminates well between jobs (and families of jobs) it takes many research studies relating a concept to other variables to firmly establish the meaning of that concept. Far more validity studies are needed before the authors could be sure that the JDS, in fact, measures what it is supposed to be measuring. The authors suggest that it is important to gather information about jobs and people's reactions to them using more than one methodology, and to check for consistency among those measures before using them in planning for change.

The substantive validity of the instrument is addressed in detail in a separate report (Hackman \& Oldham, 1974). The researchers findings are that the variables measured by the JDS relate to one another (and to external criterion variables) generally as predicted by the theory on which the instrument is based. The findings are from 658 employees working on 62 different jobs in seven organizations.

The substantive validity of the instrument has been established (Hackman \& Oldman, 1974) and the job dimensions themselves are intercorrelated as found by and (Hackman \& Lawler, 1971), (Hackman \& Oldham, 1974) and (Taber \& Taylor, 1990).

Of concern are the JDS measures of the context satisfactions and individual growth need strength. The context satisfactions are tapped by relatively few items and are intended to provide only a quick check of how satisfied people are with selected aspects of their work environment. When highly trustworthy measures of satisfaction are needed, it is advisable to the Job Descriptive Index (Smith, Kendall, \& Hulin, 1969) rather than the JDS.

The concept of growth need strength is key in the theory of work motivation underlying the JDS, and many items are devoted to assessing the strength of respondents' desires for growth. Some evidence exists regarding the validity of the growth need strength measure, and is scattered and does operate as specified in the theory; others do not. And it was unclear to the authors whether the negative findings reflect a fault of the theory, or an inadequacy of the measure or problems in research methodology. Until these issues are resolved, measures of growth need strength should be used quite cautiously in planning for work redesign.

The first study the researchers conducted was a survey of 534 employees of a major retail company. This survey had a 62 percent response rate. The average age of those responding to the survey was 37.9 years. Males accounted for 22.7 percent of the respondents' while 72.7 percent were female. 
In another study, the researchers surveyed a major manufacturing company that produces electric motors. The plant had 1,000 workers with 200 being sampled.

This study consisted of a survey given to 300 employees in a small 80 bed hospital.

The study had a 30 percent response rate. This study used the Hackman and Oldman Skills Applications 4.2 Job Diagnostic Survey consisting of 23 questions. The goal of this study is to compare the model and its results in the manufacturing, retail and service sector. The following chart summarized the demographic information about the study.

\begin{tabular}{|l|c|c|l|c|c|c|c|}
\hline Male & Female & Average Age & Single & Married & Divorced & Separated & Widowed \\
\hline 14 & 75 & 44.56 & 9 & 66 & 10 & 2 & 2 \\
\hline
\end{tabular}

\begin{tabular}{|c|c|c|c|c|c|}
\hline Skill Variety & Task Identity & $\begin{array}{c}\text { Task } \\
\text { Significance }\end{array}$ & Autonomy & Feedback & $\begin{array}{c}\text { Motivating Potential } \\
\text { Score (MPS) }\end{array}$ \\
\hline 4.05 & 3.89 & 4.48 & 3.56 & 3.36 & 49.42 \\
\hline
\end{tabular}

The next step was to compare these results with the manufacturing and retail sectors.

\begin{tabular}{|l|c|c|c|c|c|}
\hline \multicolumn{1}{|c|}{ Dimension } & $\begin{array}{c}\text { Retail Industry } \\
\text { Mean } \\
\text { (Study) }\end{array}$ & $\begin{array}{c}\text { Manufacturing } \\
\text { Industry Mean } \\
\text { (Study) }\end{array}$ & $\begin{array}{c}\text { Service Industry } \\
\text { Hospital } \\
\text { Mean } \\
\text { (Study) }\end{array}$ & $\begin{array}{c}\text { Sales Industry } \\
\text { Mean }\end{array}$ & $\begin{array}{c}\text { Manufacturing } \\
\text { Industry Mean }\end{array}$ \\
\hline Skill Variety & 4.46 & 4.89 & 4.05 & 4.8 & 4.2 \\
\hline Task Identity & 5.25 & 3.94 & 3.89 & 4.4 & 4.3 \\
\hline Task Significance & 5.59 & 5.31 & 4.48 & 5.5 & 5.3 \\
\hline Autonomy & 5.30 & 4.67 & 3.56 & 4.8 & 4.5 \\
\hline Feedback from job & 4.05 & 4.07 & 3.36 & 4.4 & 4.7 \\
\hline $\begin{array}{l}\text { High internal work } \\
\text { motivation }\end{array}$ & 5.61 & 5.18 &.--- & 5.7 & 5.3 \\
\hline MPS & 109.47 & 97.24 & 49.42 & 104.52 & 97.24 \\
\hline
\end{tabular}

When evaluating skill variety, the researchers found the retail industry studied had.41 higher scores for skill variety that the hospital studied. Also, the manufacturing industry we studied had a .84 higher score, the average for the sales industry was .75 higher and the average for the manufacturing industry was .15 higher that the hospital surveyed. The scores are close to the average for all manufacturing firms.

For task identity the scores in our survey were 1.36 higher than the scores for the hospital survey, .05 higher for the manufacturing industry studies, .51 higher for the average sales industry and .41 higher for the average the researchers found in the manufacturing industry.

When the researchers evaluated task significance, the retail industry studied was 1.11 higher and the manufacturing was .83 higher than the hospital studied. Also, the sales and manufacturing means for the overall industry were .102 and .82 higher. For autonomy, the retail and manufacturing industry studied were 1.88 and .9 higher with the average for the sales industry 2.23 higher and the average for the manufacturing industry .94 higher.

Feedback was the most interesting variable. With our study of the retail industry .69 and the manufacturing study .71 higher than the hospital we studied. Also the industry average for the sales industry was 1.04 and the average for the manufacturing industry 1.07 higher.

In comparing the motivating potential score, the retail company surveyed was 60.05 higher, the manufacturing company 47.82 higher, the average for the entire sales industry 55.1 higher and the average for the entire manufacturing industry 47.92 higher. The motivating potential score ranges from 1-125. 
Elements that lead to job satisfaction are achievement, advancement, recognition, growth, responsibility and the work itself. Contributing to dissatisfaction could be salary, status, company policy, security, supervision and working conditions.

Hackman and Oldham sought to "measure" the motivating potential of jobs. In other words, to measure the extent that a job exhibits the five characteristics listed above. Their research found that jobs scoring high in terms of a combination of these five characteristics resulted in higher job satisfaction and productivity than jobs scoring low. For a job to be intrinsically motivating, all five characteristics must be simultaneously present, to some extent.

\section{Job Characteristics Model}

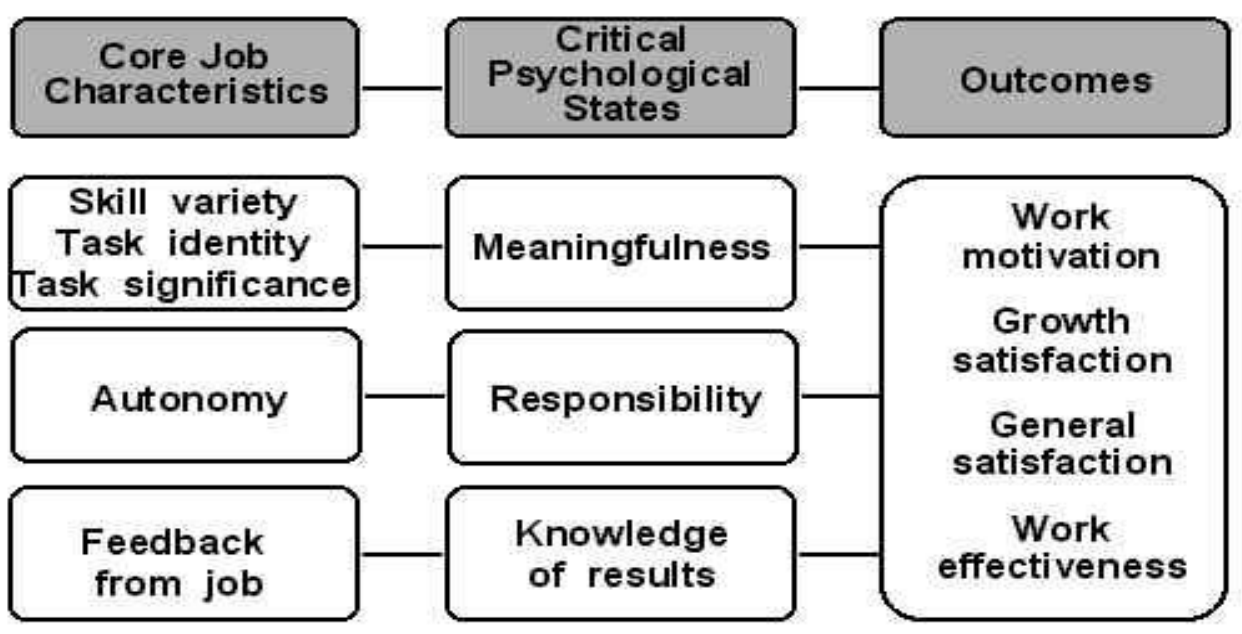

The motivating potential score is computed below:
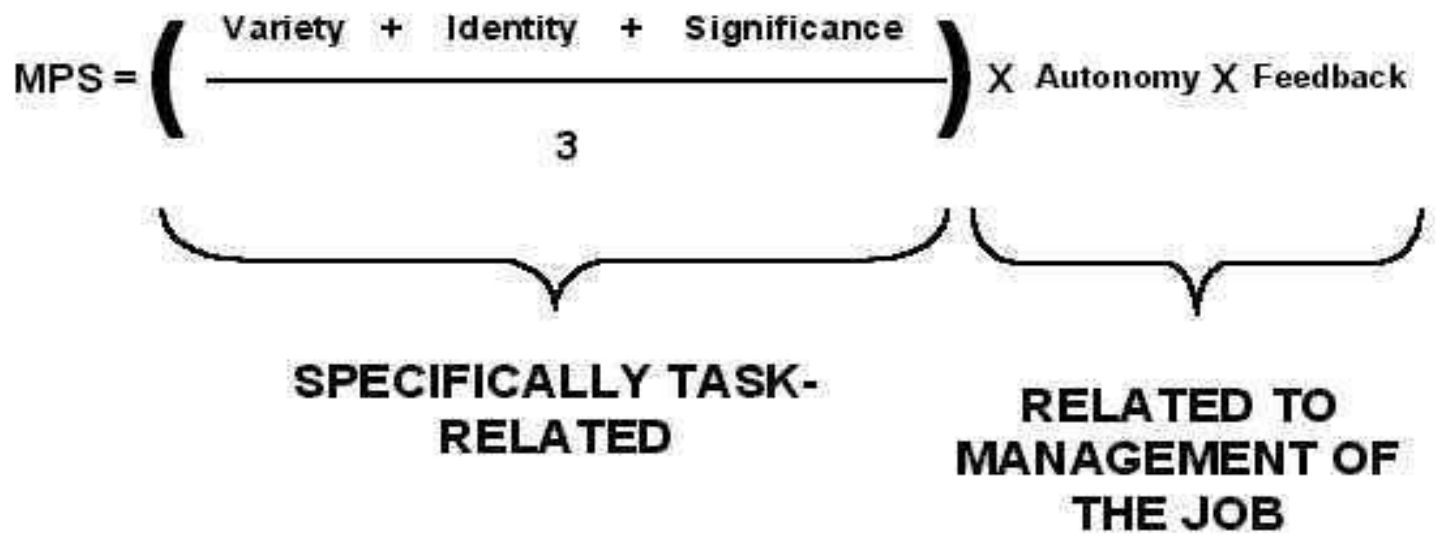

RELATED TO THE JOB 
The researchers looked specifically at the task related portion of the motivating potential score was 4.14 while the score related to management of the job was 11.29 .

It appeared there was less potential for increasing motivation in the service industry than in the study in the manufacturing, retail industires. This may be due to the type of service company the researchers surveyed. The hosptial industry due to its very nature, is a very stressful environment. Every day nurses are caring for peole that in some cases are terminol, and who they never have contact with or know how they are doing once they leave the hospital.

\section{CONCLUSIONS AND OBSERVATIONS}

The hospital survey was close to the scores of the study the researchers conducted in the retail and manufacturing sectors, as well as the industry averages for those industries. In a hospital skill variety is very important in the process of taking care of people that are in the hospital. Task idenity and task significance were also reasonable when compared to the survey and mean for the manufacturing and service industry, This is reasonable since the hospital personnel do have specific tasks to accomplish and would underestand the significance of taking care of their patents.

However, autonomy and feedback were somewhat lower than our survey groups and the average for the manufacturing and service insdustry, This may be due to the strick rules and regulations that are required in taking care of patents. There would be more autonomy in the retail and manufacturing industries. Also, in manufacturing each item a person produces can be traced back for quality control purposes, and in the retail sector you will receive immediate feedback from the customers. In the hospital industry, after patents are discharged the nurses may not see them again or know how they are doing. This is one reason for the lower scores in feedback.

\section{SUGGESTIONS FOR FUTURE RESEARCH}

The researchers suggest that futher studies be made in the hospital industry. Also there is a need to look at the hospital study by work classificaiton and gender. Also the researchers recommend futher research in other areas of the service industry.

\section{AUTHOR INFORMATION}

Dr. Jay Robbins is a Visiting Professor of Management at Ouachita Baptist University with a D.B.A. in Management from Nova Southeastern University and a Masters degree from the University of Arkansas in Operations Management. He earned his undergraduate degree in Business from Henderson State University. At Ouachita Baptist University he teaches, business communications, management information systems and small business management. His current research interests include motivation and small business strategy.

\section{REFERENCES}

1. Alderfer, Clayton P. (1972) Existence, Relatedness and Growth: Human Needs in Organization Settings, New York; Free Press 1972.

2. Alderfer, Clayton. (1969). An empirical test of a new theory of human needs. Organizational Behavior and Human Performance, May, 142-175.

3. Dunham, R.B., (1976). The measurement and dimensionality of job characteristics. Journal of Applied Psychology. 61 404-409.

4. Dunham, R.B., Aldag, R.J., \& Brief, A.P., (1977). Dimensionality of task design as measured by the job diagnostic survey. Academy of Management Journal. 20, 209-223.

5. Evans, M.G., Kiggundu, M.U., \& House, R.J. (1979). A partial test and extension of the job characteristics model of motivation. Organizational Behavior and Human Performance, 24, 354-381.

6. Herzberg, F., and Mausner, B. \& Snyderman, B. (1959). The Motivation to Work, New York: Wiley.

7. Hackman, J.R., \& Oldham, Greg R. (1975). Development of the job diagnostic survey. Journal of Applied Psychology, 60, 159-170. 
8. Hackman, J.R. \& Lawler, E.E. (1971). Employee reactions to job characteristics. Journal of Applied Psychology Monograph, 55 (191), 259-286.

9. Hackman, J.R. \& Oldham, G.R. (1974). The job diagnostic: an instrument for the diagnosis of jobs and the evaluation of job redesign projects. JSAS Catalog of Selected Documents in Psychology, 4, 148, (Ms. No. 810).

10. Hackman, J.R. \& Oldham, Greg R. (1976). Motivation through the design of work: Test of a theory. Organizational Behavior and Human Performance, 16, 250-276.

11. Hackman, J.R., \& Oldham, Greg R. (1980). Job Redesign, Mass: Addison-Wesley.

12. Hackman, J.R., \& Oldham, Greg R., Janson, Robert, \& Purdy, Kenneth, 1 (1975). A new strategy for job enrichment. California Management Review, 17 (4), 57-71.

13. Hackman, J.R., Pearce, Lone I, \& Wolfe, Jane Caminis (1978). Effects of changes in job characteristics on work attitudes and behavior: a naturally occurring quasi-experiment. Organizational Behavior and Human Performance, 21, 289-304.

14. Hackman, J.R., \& Suttle, J.L. (1977). Improving Life ar Work, Scott Foresman and Company, 1977.

15. Hackman, J.R., Oldham, Greg R. (1980). Work Redesign, Addison-Wesley

16. Oldham, Greg R. (1976). Job characteristics and internal motivation: the moderating effect of interpersonal and individual variables. Human Relations, 29 (6), 559-569.

17. Pearce, J.L. \& DunhAM, R.B., (1978). The measurement of perceived job characteristics. The job diagnostic survey versus the job characteristics inventory. Academy of Management Journal, 21, 123-128.

18. Stone E.G., \& Porter, L.W., (1979). On the use of incumbent supplied job characteristics data. Perceptual and Motor Skills. 46 751-758.

19. Taber, Tom \& Taylor, Elizabeth, (1990). A review and evaluation of the psychometric properties of job diagnostic survey. Personnel Psychology, 43 (3), 47-500.

20. Tiegs, Robert B., Tetrick, Lois E., \& Fried Yitzhak (1992). Growth need strength and context satisfactions as moderators of the relations of the job characteristics model.Journal of Management, 18 (3), 575-593. 